\title{
An economic evaluation of nivolumab for the treatment of squamous and non-squamous NSCLC in the Swedish setting
}

\author{
CAITLIN SMARE ${ }^{1 *}$ \\ MEENA VENKATACHALAM ${ }^{1}$ \\ EMMA MEDIN ${ }^{2}$ \\ MARCUS HULTBERG ${ }^{2}$ \\ JOHN R. PENROD ${ }^{3}$ \\ NADINE HERTEL ${ }^{4}$ \\ MICHAEL LEES ${ }^{5}$ \\ CHRISTOFFER HOLMBERG ${ }^{6}$ \\ ${ }^{1}$ Parexel International, London, UK \\ ${ }^{2}$ Parexel International, Stockholm, Sweden \\ ${ }^{3}$ Bristol-Myers Squibb, Princeton, NJ, USA \\ ${ }^{4}$ Bristol-Myers Squibb, London, UK \\ ${ }^{5}$ Bristol-Myers Squibb, Paris, France \\ ${ }^{6}$ Bristol-Myers Squibb, Stockholm, Sweden
}

\begin{abstract}
The cost-effectiveness of nivolumab versus docetaxel in patients with previously treated non-small cell lung cancer (NSCLC) was estimated in a cohort-based, partitioned survival model with three health states (progression-free, progressed disease, and death) and a time horizon of 15 years. The base-case model was developed using extrapolations of progression-free survival (PFS) and overall survival (OS) data from the CheckMate 017 and 057 randomized trials, and 2015 Swedish unit costs. An annual discount rate of 3\% was applied. Base-case time-on-treatment was based on PFS (CheckMate 017) or time-totreatment discontinuation (CheckMate 057), depending on whether PFS was a close proxy for time-on-treatment. Data extrapolations from CheckMate 017 and 057 were validated against external trial and registry data. Model utilities were derived from CheckMate 017 and 057 with UK weights (base-case) and Swedish weights (scenario analysis). Uncertainty was assessed using sensitivity analyses adjusted for clinical, utility, and cost data. Outcomes included incremental cost per quality-adjusted life-year (QALY) gained. The base-case model showed that nivolumab was associated with QALY gains of 0.72 (squamous) and 0.81 (non-squamous) versus docetaxel at an incremental cost of 734,573 SEK $(€ 69,174)$ and 999,032 SEK $(€ 94,078)$, respectively. This resulted in an incremental cost per QALY gained for nivolumab versus docetaxel of 1,013,697 SEK $(€ 95,459)$ and $1,231,664$ SEK $(€ 115,985)$ in squamous and non-squamous NSCLC, respectively. Scenario analysis utilizing Swedish utility weights resulted in slightly lower incremental cost per QALY gained of 855,505 SEK ( $€ 80,562)$ (squamous) and $1,165,401$ SEK $(€ 109,745)$ (nonsquamous). Deterministic sensitivity analysis showed that utility weights, treatment costs, discount rates, and body weight were key drivers of cost-effectiveness. Overall, the model showed that cost-effectiveness was driven by nivolumab price, but nivolumab remained cost-effective in squamous and non-squamous NSCLC in accordance with previous appraisals by the Dental and Pharmaceutical Benefits Agency (Tandvårds- och läkemedelsförmånsverket) and New Therapies Council in Sweden.
\end{abstract}

* Correspondence to: Caitlin Smare, Parexel Access Consulting, Evergreen Building, 160 Euston Road. London, UK NW1 2DX. Phone: +44 207 121-1774. Email: Caitlin.Smare@parexel.com.

Published: Online December 2019. dx.doi.org/10.5617/njhe.5453 


\section{JEL classification: $\mathrm{I} 15$}

Key words: cost-effectiveness analysis, nivolumab, programmed death-1 inhibitor, NSCLC, Sweden

\section{Introduction}

Lung cancer is the most common cancer-related cause of death in Europe (Union for International Cancer Control 2018). In Sweden, an estimated 3,600 people die of lung cancer and around 4,000 cases are diagnosed annually (NORDCAN Association of the Nordic Cancer Registries 2019). Non-small cell lung cancer (NSCLC) accounts for $85 \%$ of lung cancer (Zappa et al. 2016). It has two main sub-types based on cell histology: non-squamous (70-75\%), which includes adenocarcinoma and large cell lung cancer, and squamous (2530\%) (Zappa et al. 2016).

The prognosis for patients with NSCLC who have not responded to first-line treatment is poor and, until recently, treatment options were limited. Nivolumab, a fully human immunoglobulin G4 programmed death-1 immune checkpoint inhibitor antibody, was granted European Medicines Agency approval for the treatment of adults with locally advanced or metastatic squamous NSCLC and non-squamous NSCLC after prior chemotherapy in 2015 and 2016, respectively (European Medicines Agency 2019). The efficacy of nivolumab in locally advanced or metastatic NSCLC after prior chemotherapy has been demonstrated in two pivotal randomized, open-label, international Phase III trials known as CheckMate 017 (Brahmer et al. 2015) and CheckMate 057 (Borghaei et al. 2015). Both trials compared nivolumab with docetaxel, with the primary endpoint of overall survival (OS) and a secondary endpoint of progression-free survival (PFS).

CheckMate 017 enrolled 272 patients with advanced squamous NSCLC that had progressed during or after one prior platinum-containing chemotherapy regimen. Prior maintenance therapy as part of first-line treatment was allowed. Patients were excluded if they had more than one prior line of therapy for metastatic disease. In this trial, the median OS was 9.2 months with nivolumab versus 6.0 months with docetaxel and, at 1 year, the OS rate was $42 \%$ for nivolumab compared with $24 \%$ for docetaxel (Brahmer et al. 2015). CheckMate 057 enrolled 582 patients with advanced non-squamous NSCLC that had progressed following treatment with one prior platinum-doublet chemotherapy (maintenance was allowed). Patients with known epidermal growth factor receptor mutation or anaplastic lymphoma kinase translocation could have previously received or could be receiving one additional private line of tyrosine kinase inhibitor therapy, and approximately $11 \%$ of patients had received more than one prior line of treatment. In this trial, the median OS was 12.2 months and 9.4 months, and 1-year OS rates were 51\% and $39 \%$ in the nivolumab and docetaxel groups, respectively (Borghaei et al. 2015).

In Sweden, economic models for nivolumab in squamous and non-squamous NSCLC were submitted to the Dental and Pharmaceutical Benefits Agency (Tandvårds- och läkemedelsförmånsverket [TLV]) in November 2015 and March 2016, respectively (Tandvårds- och läkemedelsförmånsverket 2017, Tandvårds- och läkemedelsförmånsverket 2015). Following two separate histology-specific, independent evaluations by the TLV, nivolumab was recommended for use by the New Therapies Council as a treatment option in previously treated squamous and non-squamous NSCLC; this council is a group of experts that make recommendations on new drugs to Swedish county councils. This study presents a cost-effectiveness analysis of nivolumab in the treatment of advanced NSCLC in Sweden that was based on the models submitted to the TLV. 


\section{Methods}

\subsection{Cost-effectiveness model}

A cohort-based, partitioned survival model was developed with three mutually exclusive health states: progression-free, progressed-disease, and death. All patients entered the model in the progression-free health state. This model aimed to evaluate the incremental costeffectiveness of nivolumab versus docetaxel for advanced (metastatic; Stage IIIb/IV) squamous and non-squamous NSCLC that had progressed during or after platinum-doublet chemotherapy. At the point of conducting the analysis, a minimum follow-up of 12 months was available for CheckMate 017, and a minimum follow-up of 18 months was available for CheckMate 057. Therefore, the modelling method required the extrapolation of PFS and OS data from the trials to the defined time horizon for the evaluation. The cumulative survival probabilities for PFS and OS were used to estimate the number of patients occupying the progression-free, progressed-disease, and death states over time. The model adopted the lifetime perspective of an advanced NSCLC patient, with a time horizon of 15 years. A cycle length of 1 week was selected as this period is the largest common denominator between the cycle lengths of nivolumab (4 weeks) and docetaxel (3 weeks) administration. The model structure is shown in Figure 1.

Parametric curves were fitted to OS and PFS data from the CheckMate 017 and CheckMate 057 trials, using guidelines from the National Institute for Health and Care Excellence (Latimer 2011). Log-cumulative hazards, log-cumulative odds, and standardized normal plots were generated for the OS and PFS data from the CheckMate 017 and CheckMate 057 trials. Grambsch and Therneau correlation tests between Schoenfeld residuals and the log of time were also performed. These analyses were used to assess whether the comparative treatment effects between nivolumab and docetaxel could be modelled and extrapolated using the assumption of proportional hazards, proportional odds, or an accelerated failure time effect. In cases where the proportional effects assumptions were violated, parametric distributions were fitted to each treatment arm independently.

A number of standard parametric and cubic spline models were tested. The choice of distribution for each arm was selected based on a) statistical goodness-of-fit and b) clinical validation. For PFS and OS goodness-of-fit was based on Akaike information criterion (AIC) statistics, Bayesian information criterion (BIC) statistics, and visual inspection. Clinical plausibility of extrapolated survival curves was assessed by comparing extrapolated data against clinical trials of nivolumab with longer follow-up than the two pivotal Phase III trials and real-world data sources. For nivolumab, longer follow-up was available through two sources: CheckMate 003 (Gettinger et al. 2015) and CheckMate 063 (Rizvi et al. 2015). CheckMate 003 was a Phase IB, open-label, multicentre, multidose, dose-escalation trial evaluating the safety, antitumour activity, and pharmacokinetics of nivolumab as a single agent in previously treated patients with advanced melanoma, NSCLC, renal cell carcinoma, castration-resistant prostate cancer, or colorectal cancer. As this trial presents the longest survival follow-up of patients treated with nivolumab, the NSCLC cohort of CheckMate 003 was used to help validate the choice of parametric curve for PFS and OS. CheckMate 063 was a single-arm, Phase II trial evaluating the efficacy of nivolumab in third-line or greater advanced squamous NSCLC. Therefore, this trial was used to help validate the choice of parametric survival model selected for PFS and OS in squamous NSCLC. Both CheckMate 003 and CheckMate 063 exhibited a plateau in OS and durable survival that is characteristic of treatment with immunotherapy. Given the model had a time horizon of 15 years, validation of long-term extrapolated survival for both docetaxel and nivolumab had to rely on conditional survival data from real-world data sets 
during the period in which no follow-up from any nivolumab trial was available: the Surveillance, Epidemiology, and End Results (SEER) Program data set of the US National Cancer Institute; and the national cancer registries of Sweden and Norway (Bristol-Myers Squibb 2015a, KREFT Registeret 2015, National Cancer Institute 2019, Regionala Cancercentrum I Samverkan 2014). The parametric curve selected for nivolumab OS had to meet the criterion of having a higher conditional survival year-on-year than that of docetaxel. Lastly, base-case survival curves selected, nivolumab trial data from CheckMate 003 and CheckMate 063, and real-world data sources utilized for validation were discussed with clinical experts to further substantiate clinical plausibility.
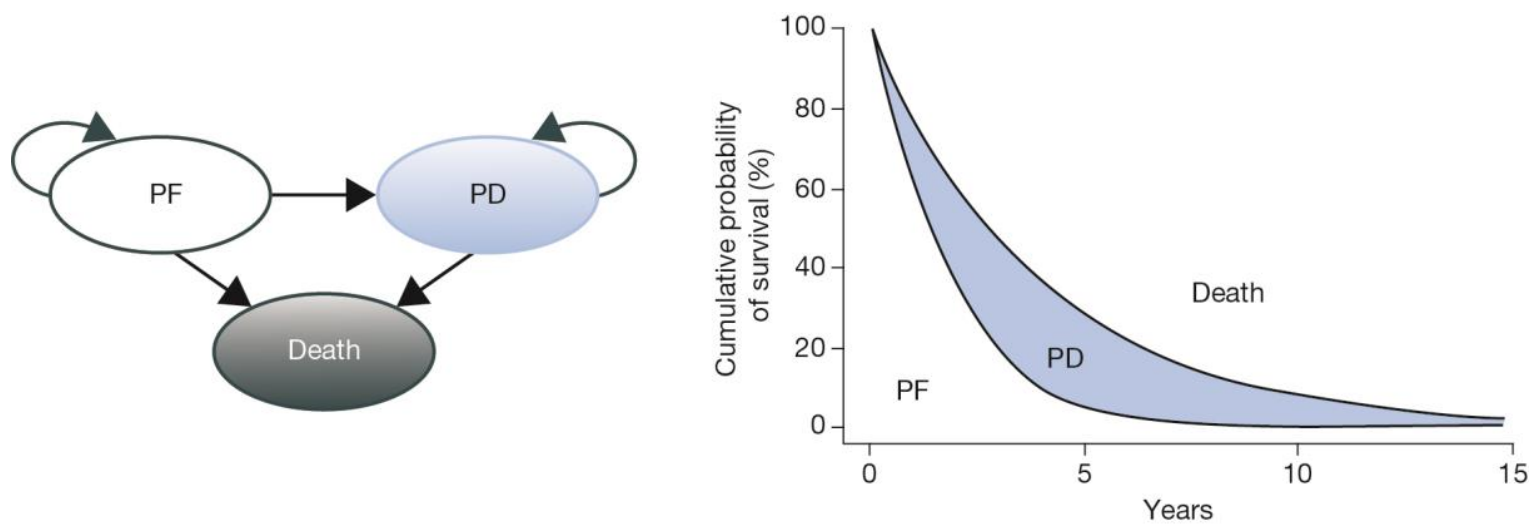

Figure 1: Health state structure of the economic model

$\mathrm{PD}=$ progressed-disease; $\mathrm{PF}=$ progression-free.

The economic model assumed that patients received the treatment of interest if they were progression-free, i.e. whilst in the progression-free health state. However, the clinical trial protocols for CheckMate 017 and CheckMate 057 allowed the clinical investigators to continue treatment with nivolumab beyond progression as defined by Response Evaluation Criteria in Solid Tumors (RECIST) v1.1 (Eisenhauer et al. 2009), if the investigator assessed that the patient was receiving clinical benefit and did not have an unacceptable level of side effects from the trial drug. In addition, patients could also discontinue either treatment before RECIST v1.1-defined progression for several reasons, including toxicity. Therefore, both PFS and time-to-treatment discontinuation data were analysed in each trial to determine which data were most appropriate to calculate the proportion of patients in the progressionfree health state and serve as a proxy for treatment duration in the base-case.

Health state utilities for patients in the progression-free or progressed-disease health state were derived using EuroQoL-5D 3-level questionnaire data collected in the CheckMate 017 and CheckMate 057 trials, and country-specific weights for the UK and Sweden were applied. UK weights (Dolan 1997) were used for the base-case and a scenario analysis was conducted using the Swedish weights (Burstrom et al. 2014). The utility for death was assumed to be 0 . The models included the cost associated with treatment acquisition, treatment administration, disease management, treatment monitoring, subsequent treatment, terminal care, and adverse events. All costs were based on 2015 Swedish-specific unit costs. All unit costs are summarized in Table S1 (Apoteket 2015, NordDRG 2013, NordDRG 2014, Södra Regionvårdsnämnden 2014, Södra Regionvårdsnämnden 2015, Tandvårds- och läkemedelsförmånsverket 2015). An annual discount rate of $3 \%$ was applied to both costs and health outcomes in line with guidance from the TLV (Tandvårds- och läkemedelsförmånsverket 2017). 
The models included both deterministic sensitivity analysis (DSA) and probabilistic sensitivity analysis (PSA) for key parameters (Table S2). In addition, scenario analyses were undertaken to estimate the impact of alternative maximum periods of treatment duration for nivolumab. Although the trial protocols for CheckMate 017 and CheckMate 057 specified that patients should receive nivolumab until progression or toxicity, other nivolumab trials have specified or evaluated treatment up to a maximum duration. For example, CheckMate 003 (Gettinger et al. 2015) implemented a treatment-stopping rule of around 2 years (96 weeks). Therefore, patients in CheckMate 003 who remained in progression-free received no treatment after 96 weeks and the OS measured in the follow-up reflects a maximum duration of treatment (Table S3 and Table S4) (Antonia et al. 2014, Brahmer et al. 2017, Brahmer et al. 2015, Bristol-Myers Squibb 2015a, Bristol-Myers Squibb 2015b, BristolMyers Squibb 2017, Font et al. 2017, Gettinger et al. 2015, KREFT Registeret 2015, Regionala Cancercentrum I Samverkan 2014).

Disease-management costs were assigned per model cycle in the progression-free and progressed-disease health states. Resource use related to disease management in each health state was sourced through interviews with three clinical experts in the treatment of NSCLC (KOL: Swedish NSCLC clinical expert 2015, Socialstyrelsen 2015, Södra Regionvårdsnämnden 2018). Unit costs of each resource use item were sourced from regional price lists and tariffs for the Swedish diagnosis-related groups (DRGs) to estimate a unit cost per model cycle. Costs for patients in the progression-free and progressed-disease health states amounted to 2,020.06 SEK (€196.96) per 4 weeks, and 1,281.09 SEK (€124.91) per 4 weeks, respectively. In the model, the cost per dose of nivolumab was calculated by optimizing the combination of the two available vial sizes and minimizing wastage. The cost of preparing the drug was provided by the TLV; the cost of drug administration and associated lab tests were sourced from a regional price list (Södra Regionvårdsnämnden 2018). Unit costs associated with the management of grade $3 / 4$ treatment-related adverse events that occurred during the treatment phase were applied to the incidence of adverse events by using the Swedish tariffs for the respective DRGs. Interviews with clinical experts were conducted in order to validate the applied costs and resource use per adverse event (KOL: Swedish NSCLC clinical expert 2015).

\subsection{Analysis for squamous NSCLC}

The cost-effectiveness analysis for squamous NSCLC compared nivolumab with docetaxel. Docetaxel was determined to be the relevant comparator to nivolumab at the time of submission. Clinical inputs such as OS, PFS, incidence of grade 3/4 adverse events, and utility estimates by health state were derived directly using patient-level data from CheckMate 017. Comparison of the Kaplan-Meier curves for PFS and time-to-treatment discontinuation for nivolumab demonstrated that the two curves were almost superimposed, indicating that any extrapolation of PFS would be similar to time-to-treatment discontinuation and the two options would estimate similar treatment duration values. For the squamous NSCLC analysis, PFS was therefore used as an estimate of treatment duration.

There was evidence that the proportional hazards assumption held between the OS arms for nivolumab and docetaxel in CheckMate 017. For the base-case analysis, OS for docetaxel was extrapolated by fitting a log-logistic curve to the docetaxel data; nivolumab OS was extrapolated by applying the hazard ratio (HR) reported in the CheckMate 017 trial to the docetaxel data (HR: $0.59 ; 95 \%$ confidence interval: $0.44,0.79 ; \mathrm{p}<0.001$ ). The loglogistic model was chosen because it provided a good fit to the observed data according to AIC/BIC criteria (Table S5) and visual inspection and was consistent with the conditional survival estimates from external data sets in the long-term. These external data sets included 
CheckMate 003 (Gettinger et al. 2015) and CheckMate 063 (Rizvi et al. 2015) for nivolumab, and SEER data for docetaxel and nivolumab following the last landmark available from the CheckMate 003 and 063 trials. In the original TLV submission, the minimum follow-up was 3 years in CheckMate 003 and 12 months in CheckMate 017. An update of CheckMate 003 with a minimum follow-up of 5 years and an update of CheckMate 017 with a minimum follow-up of 3 years has since been presented (Brahmer et al. 2017, Font et al. 2017). The longer follow-ups further confirm the appropriateness of the chosen log-logistic model for nivolumab OS (Table S4) (Antonia et al. 2014, Brahmer et al. 2015, Bristol-Myers Squibb 2017, Font et al. 2017, Gettinger et al. 2015).

The proportional hazards assumption did not hold between the PFS arms for nivolumab and docetaxel. Therefore, a dependent 2-knot spline hazards model was fitted to both the nivolumab and docetaxel arms and adjusted for shape and scale. An interaction term on the gamma 1 allowed the model to fit both arms well, despite the non-proportional hazards. Visual inspection and AIC/BIC statistics (Table S5) were used to assess the fit to the Kaplan-Meier data. For nivolumab, the long-term extrapolation was validated using data from the CheckMate 003 (Gettinger et al. 2015) and CheckMate 063 (Rizvi et al. 2015) trials (Table S6) (Antonia et al. 2014, Brahmer et al. 2015). For docetaxel there were no real-world data sets that provided long-term PFS estimates; therefore, validation was limited to CheckMate 017 data. However, a very small proportion of patients remained in the progression-free state for docetaxel at 1 year, minimizing the uncertainty of the extrapolated curve (Table S7).

The base-case OS and PFS curves over 18 months and extrapolated over a lifetime horizon are displayed in Figure 2 and Figure 3, respectively. Health state utilities for patients in the progression-free and progressed-disease health states were tested to assess statistically significant differences by treatment arm. No statistically significant differences were seen; therefore, health state utilities were not differentiated by treatment (Table 1) (Burstrom et al. 2014, Dolan 1997).

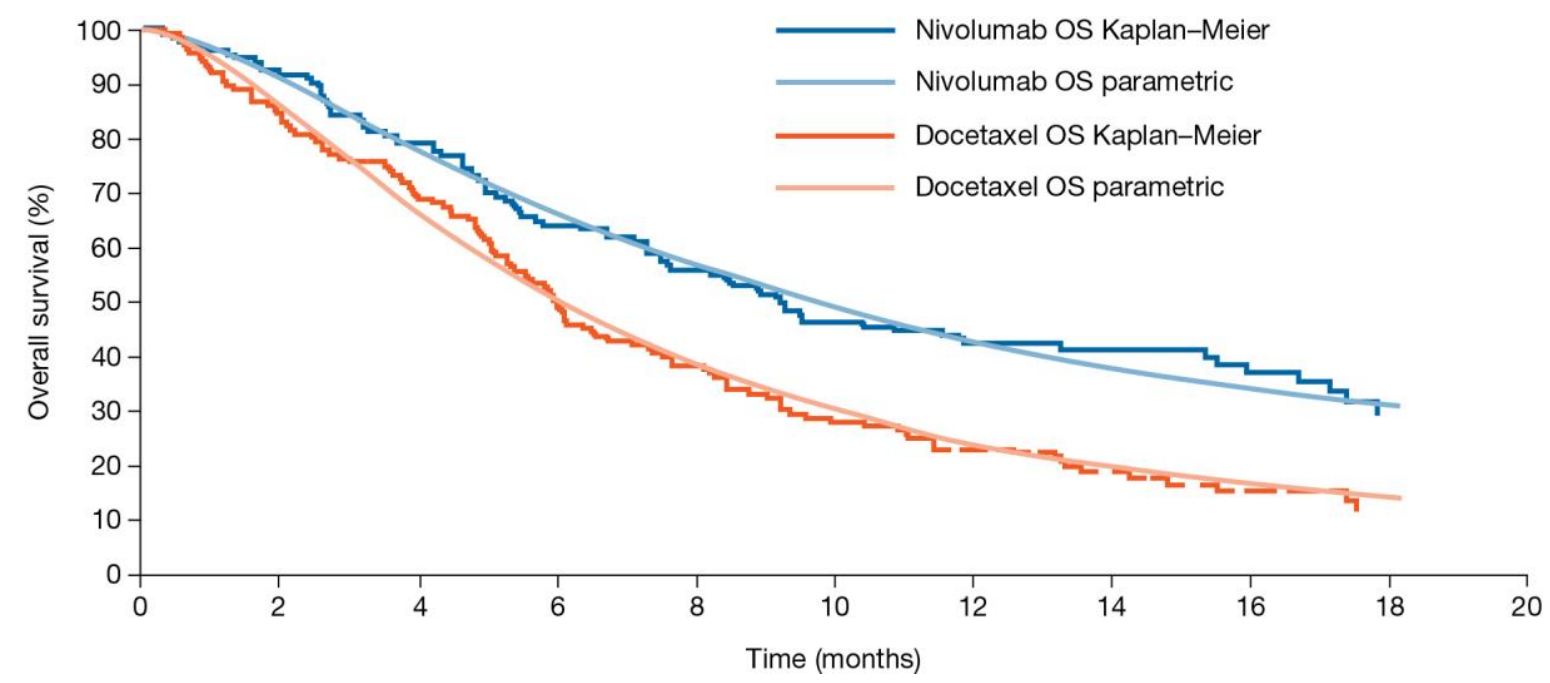

Figure 2: Parametric curves for OS over 18 months (squamous analysis; CheckMate 017)

OS = overall survival 


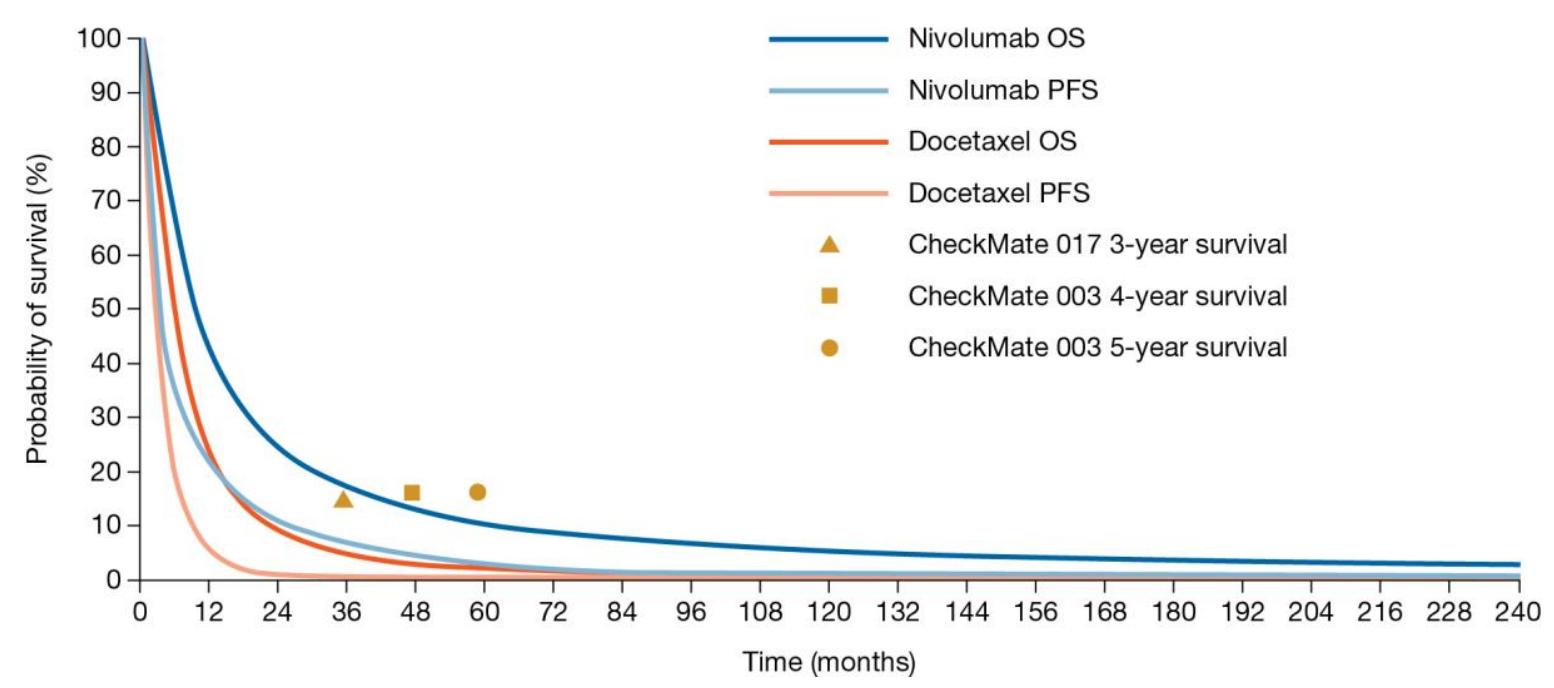

Figure 3: Parametric curves for OS and PFS extrapolated over a lifetime horizon with validation using nivolumab trials with longer follow-up (squamous analysis; CheckMate 017)

OS = overall survival; PFS = progression-free survival .

Table 1: Mean EQ-5D-3L values from the squamous analysis (CheckMate 017) by health state

\begin{tabular}{lll}
\hline Country (reference for tariff) & $\begin{array}{l}\text { Progression-free } \\
\text { health state utility } \\
\text { Mean }(95 \% \mathrm{CI})\end{array}$ & $\begin{array}{l}\text { Progressed disease } \\
\text { health state utility } \\
\text { Mean }(95 \% \mathrm{CI})\end{array}$ \\
\hline UK (Dolan 1997) & $0.750(0.734,0.765)$ & $0.592(0.550,0.634)$ \\
Sweden (Burstrom et al. 2014) & $0.841(0.833,0.849)$ & $0.764(0.746,0.781)$ \\
\hline
\end{tabular}

$\mathrm{CI}=$ confidence interval; EQ-5D-3L = EuroQoL-5D 3-level questionnaire.

\subsection{Analysis for non-squamous NSCLC}

As for squamous NSCLC, docetaxel was determined to be the relevant comparator to nivolumab at the time of submission. As with the squamous analysis, clinical inputs such as OS, PFS, incidence of grade 3/4 adverse events, and utility estimates by health state were derived directly using patient-level data from CheckMate 057.

In contrast to the squamous analysis, comparison of time-to-treatment discontinuation and PFS data for non-squamous NSCLC demonstrated that the KaplanMeier curve for time-to-treatment discontinuation was slightly above the Kaplan-Meier curve for PFS for nivolumab, implying that some patients remained on treatment beyond progression, as was allowed per trial design. Considering this difference, survival curves were fitted to both PFS and time-to-treatment discontinuation and included in the economic model. As a conservative assumption, time-to-treatment discontinuation was used to model treatment duration in the base-case, and a scenario analysis utilized PFS data.

The proportional hazards assumption was violated for OS, PFS, and time-totreatment discontinuation, given the Kaplan-Meier curves for nivolumab and docetaxel crossed within the follow-up period. Therefore, parametric curves were fitted to the KaplanMeier data for each treatment arm and outcome independently. In the base-case for nivolumab OS, PFS, and time-to-treatment discontinuation the log-normal, 1-knot spline odds, and 1-knot spline odds model were selected, respectively. For docetaxel OS, PFS, and 
time-to-treatment discontinuation the generalized gamma, log-normal, and generalized gamma model were selected, respectively.

For OS, PFS, and time-to-treatment discontinuation the goodness-of-fit for each distribution was assessed using AIC/BIC statistics and visual inspection (Tables S8A and S8B). As with the squamous analysis, for nivolumab OS and PFS long-term extrapolations were validated against CheckMate 003 (Gettinger et al. 2015). For OS, in the original TLV submission the minimum follow-up was 3 years in CheckMate 003 and 18 months in CheckMate 057. An update of CheckMate 003 with a minimum follow-up of 5 years and an update of CheckMate 057 with a minimum follow-up of 3 years has since been presented (Brahmer et al. 2017, Font et al. 2017), further confirming the appropriateness of the chosen log-normal model for nivolumab OS. For docetaxel OS and nivolumab OS, following the landmark available from CheckMate 003, conditional survival predicted from the long-term extrapolation of these parametric curves was then validated against conditional survival from external data sets, including SEER, and the national cancer registries of Sweden and Norway (Table A3) (Brahmer et al. 2017, Brahmer et al. 2015, Bristol-Myers Squibb 2015a, Bristol-Myers Squibb 2015b, Font et al. 2017, KREFT Registeret 2015, Regionala Cancercentrum I Samverkan 2014). For docetaxel PFS and time-to-treatment discontinuation there were no real-world data sets which provided long-term estimates, and therefore, validation was limited to CheckMate 057 data. However, a very small proportion of patients remained in the progression-free state for docetaxel at 1 year, minimizing the uncertainty of the extrapolated curve (Table S7).

OS and PFS curves used in the base-case analysis, over 30 months and extrapolated over a lifetime horizon, are presented in Figure 4 and Figure 5. In CheckMate 057, health state utilities by treatment arm did show statistically significant differences; therefore, treatment-specific utilities were used for each health state (see Table 2) (Burstrom et al. 2014, Dolan 1997).

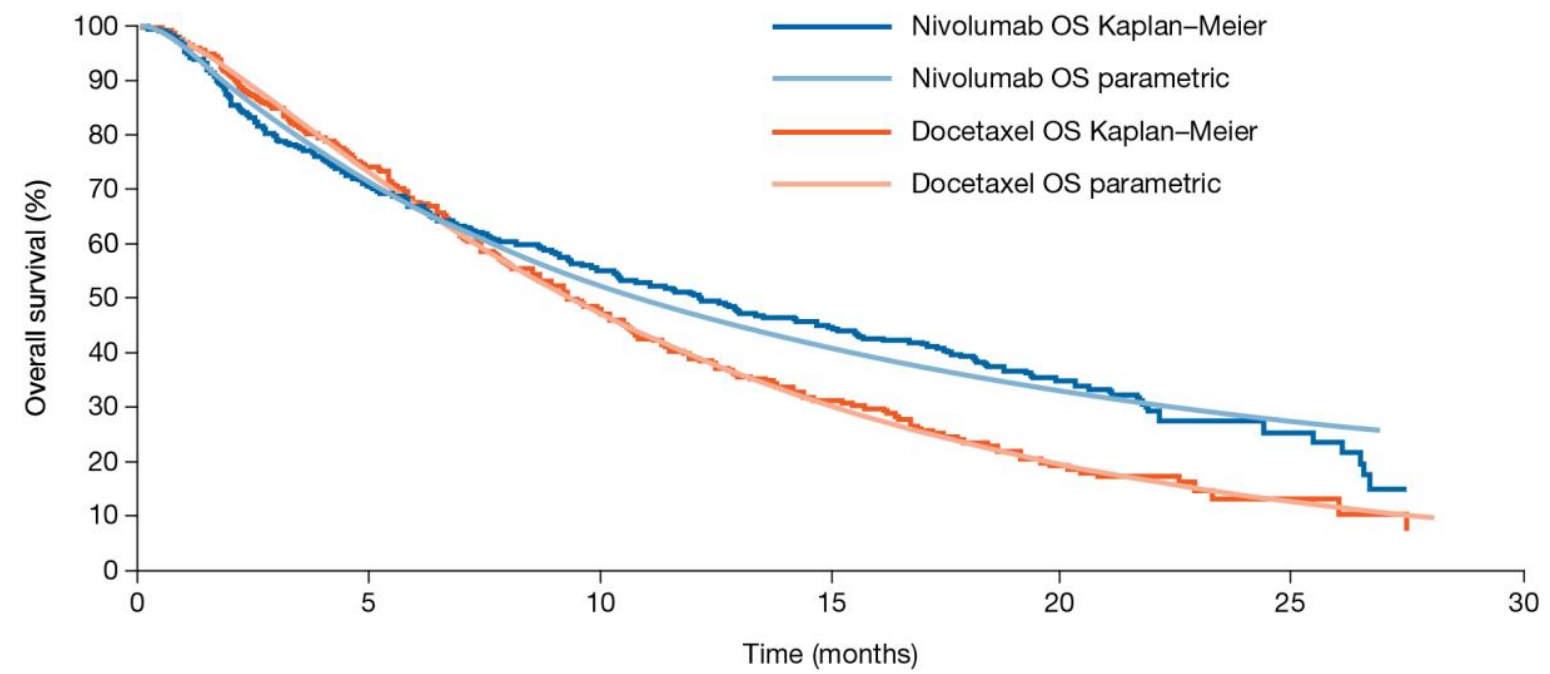

Figure 4: Parametric curves for OS over 30 months (non-squamous analysis; CheckMate 057)

OS $=$ overall survival 


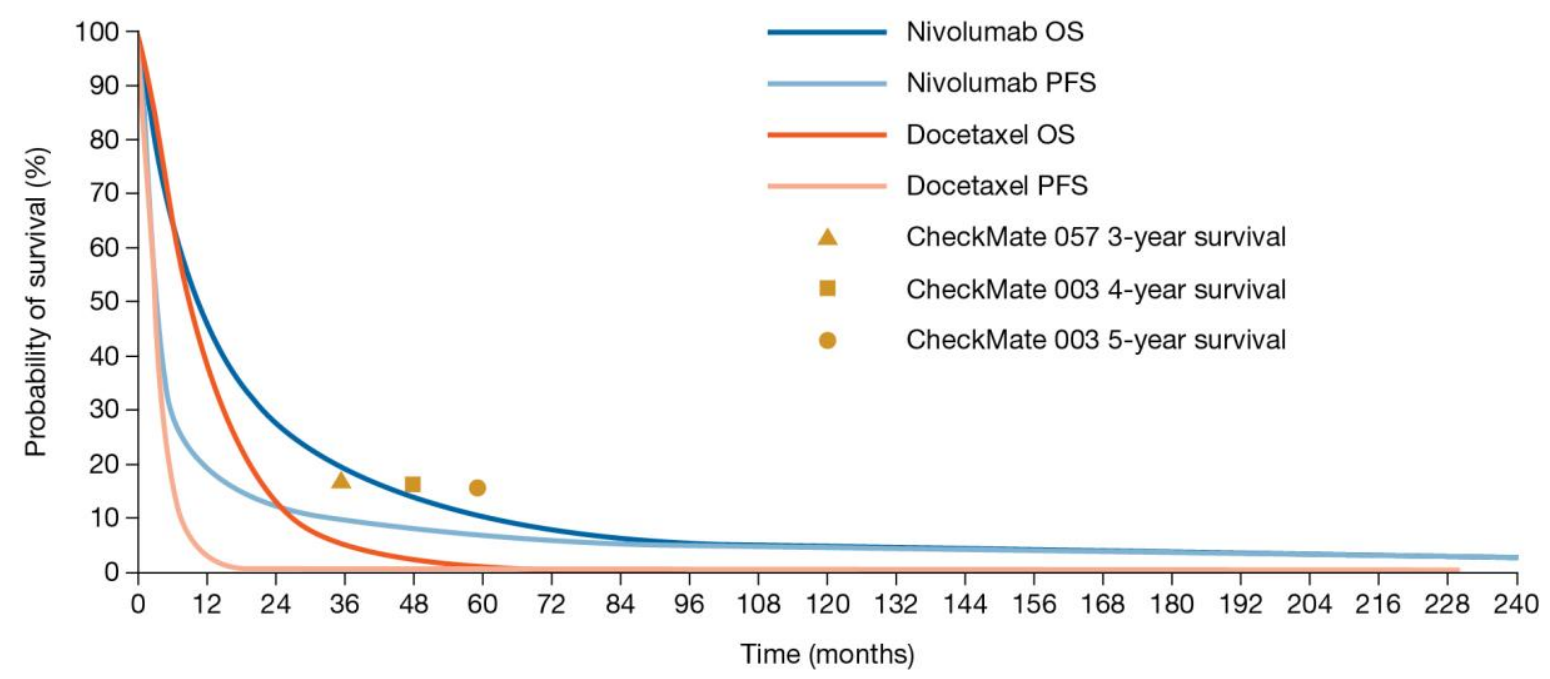

Figure 5: Parametric curves for OS and PFS extrapolated over a lifetime horizon with validation using nivolumab trials with longer follow-up (nonsquamous analysis; CheckMate 057)

OS = overall survival; PFS = progression-free survival .

Table 2: Mean EQ-5D-3L values from the non-squamous analysis (CheckMate 057) by treatment and health state

\begin{tabular}{llll}
\hline Treatment & $\begin{array}{l}\text { Country } \\
\text { (reference for tariff) }\end{array}$ & $\begin{array}{l}\text { Progression-free } \\
\text { health state utility } \\
\text { Mean }(95 \% \mathrm{CI})\end{array}$ & $\begin{array}{l}\text { Progressed disease } \\
\text { health state utility } \\
\text { Mean }(95 \% \mathrm{CI})\end{array}$ \\
\hline \multirow{2}{*}{ Nivolumab } & UK (Dolan 1997) & $0.761(0.747,0.774)$ & $0.716(0.687,0.744)$ \\
& Sweden (Burstrom et al. 2014) & $0.853(0.846,0.859)$ & $0.830(0.817,0.844)$ \\
Docetaxel & UK (Dolan 1997) & $0.716(0.703,0.730)$ & $0.638(0.597,0.678)$ \\
& Sweden (Burstrom et al. 2014) & $0.825(0.819,0.832)$ & $0.795(0.778,0.813)$ \\
\hline
\end{tabular}

$\mathrm{CI}=$ confidence interval; EQ-5D-3L = EuroQoL-5D 3-level questionnaire.

\section{Results}

\subsection{Squamous NSCLC}

For squamous NSCLC, the incremental cost per quality-adjusted life year (QALY) amounted to $1,013,697$ SEK $(€ 95,459)$ for nivolumab versus docetaxel, based on an incremental cost of 734,573 SEK $(€ 69,174)$ and an incremental QALY gain of 0.72 (Table $3)$.

An overview of the results of the scenario analyses conducted for squamous NSCLC is provided in Table S9. Applying a treatment-stopping rule at 96 weeks reduced the incremental cost per QALY for nivolumab versus docetaxel to 719,268 SEK $(€ 67,733)$ per QALY. Using Swedish utility weights rather than UK utility weights resulted in an incremental cost of 855,505 SEK $(€ 80,562)$ per QALY. Applying no discount rate to costs or outcomes resulted in an incremental cost of 948,971 SEK $(€ 89,364)$ per QALY.

DSA for nivolumab versus docetaxel revealed that the HR applied to model OS for nivolumab, utility weights, and treatment cost were the most important drivers of costeffectiveness (Figure 6).

PSA for nivolumab versus docetaxel resulted in an incremental cost per QALY of $1,045,419$ SEK $(€ 98,446)$. Of the 1,000 iterations run for the PSA, $95 \%$ of these fell within a range of 547,802 SEK $(€ 51,586)$ to $2,534,953$ SEK $(€ 238,714)$ incremental cost per 
QALY. When applying a treatment-stopping rule at 96 weeks, the PSA for nivolumab versus docetaxel resulted in an incremental cost per QALY of 713,318 SEK (€67,172). Of the 1,000 iterations run for the PSA, $95 \%$ fell within a range of $414,362 \operatorname{SEK}(€ 39,020)$ to 1,931,261 SEK $(€ 181,865)$ incremental cost per QALY. The cost-effectiveness acceptability curves (CEACs) illustrating these findings are shown in Figure S1 and Figure S2.

Table 3: Base-case cost-effectiveness results (squamous analysis; CheckMate 017)

\begin{tabular}{|c|c|c|c|c|c|c|}
\hline & $\begin{array}{l}\text { Incremental } \\
\text { costs (SEK) }\end{array}$ & $\begin{array}{l}\text { Incremental } \\
\text { LY }\end{array}$ & $\begin{array}{l}\text { Incremental } \\
\text { QALYs }\end{array}$ & \multicolumn{2}{|c|}{$\begin{array}{l}\text { Incremental cost per LYG } \\
\text { (SEK) }\end{array}$} & $\begin{array}{l}\text { Incremental } \\
\text { cost per } \\
\text { QALY } \\
\text { (SEK) }\end{array}$ \\
\hline $\begin{array}{l}\text { Nivolumab } \\
\text { vs. } \\
\text { docetaxel }\end{array}$ & 734,573 & 1.16 & 0.72 & \multicolumn{2}{|l|}{632,708} & $1,013,697$ \\
\hline \multirow{2}{*}{\multicolumn{2}{|c|}{ Total costs (SEK) }} & \multicolumn{5}{|c|}{ Cost breakdown (SEK) } \\
\hline & & $\begin{array}{l}\text { Disease } \\
\text { management } \\
\text { costs }\end{array}$ & $\begin{array}{l}\text { Treatment } \\
\text { acquisitions } \\
\text { costs }\end{array}$ & $\begin{array}{l}\text { Treatment } \\
\text { administration } \\
\text { costs }\end{array}$ & $\begin{array}{l}\text { Monitoring } \\
\text { costs }\end{array}$ & $\begin{array}{l}\text { Adverse } \\
\text { event costs }\end{array}$ \\
\hline Nivolumab & 898,160 & 149,735 & 700,452 & 42,187 & 4,345 & 1,440 \\
\hline Docetaxel & 163,587 & 105,698 & 21,609 & 25,252 & 3,347 & 7,681 \\
\hline \multirow{2}{*}{\multicolumn{2}{|c|}{ Total QALYs }} & \multicolumn{4}{|c|}{ QALY breakdown } & \\
\hline & & \multicolumn{2}{|c|}{ Disease state } & \multicolumn{2}{|c|}{ Adverse events } & \\
\hline Nivolumab & 1.26 & \multicolumn{2}{|l|}{1.27} & \multicolumn{2}{|l|}{-0.01} & \\
\hline Docetaxel & 0.54 & \multicolumn{2}{|l|}{0.54} & \multicolumn{2}{|l|}{-0.05} & \\
\hline
\end{tabular}

$\mathrm{LY}=$ life years; $\mathrm{LYG}=$ life years gained; $\mathrm{QALY}=$ quality-adjusted life year; SEK = Swedish Kroner.

\subsection{Non-squamous NSCLC}

For non-squamous NSCLC, the incremental cost per QALY was $1,231,664$ SEK $(€ 115,985)$ for nivolumab versus docetaxel, based on an incremental cost of 999,032 SEK (€94,078) and an incremental QALY gain of 0.81 (Table 4).

Table S10 provides an overview of the scenario analyses of costs per QALY for nivolumab versus docetaxel conducted for non-squamous NSCLC. Using PFS data instead of time-to-treatment discontinuation data to model treatment duration resulted in an incremental cost of $1,159,286$ SEK $(€ 109,169)$ per QALY. Applying a treatment-stopping rule at 96 weeks yielded an incremental cost of 593,702 SEK $(€ 55,908)$ per QALY. Using Swedish utility weights resulted in an incremental cost of $1,165,401$ SEK $(€ 109,745)$ per QALY. Applying no discount rate to costs or outcomes resulted in an incremental cost of 1,203,977 SEK $(€ 113,377)$ per QALY.

DSA demonstrated that changes to body weight (which defines the amount of drug administered and, hence, the drug costs), utility value used for the progression-free health state, and discount rates (outcomes) were the most important drivers of cost-effectiveness (Figure 7). 


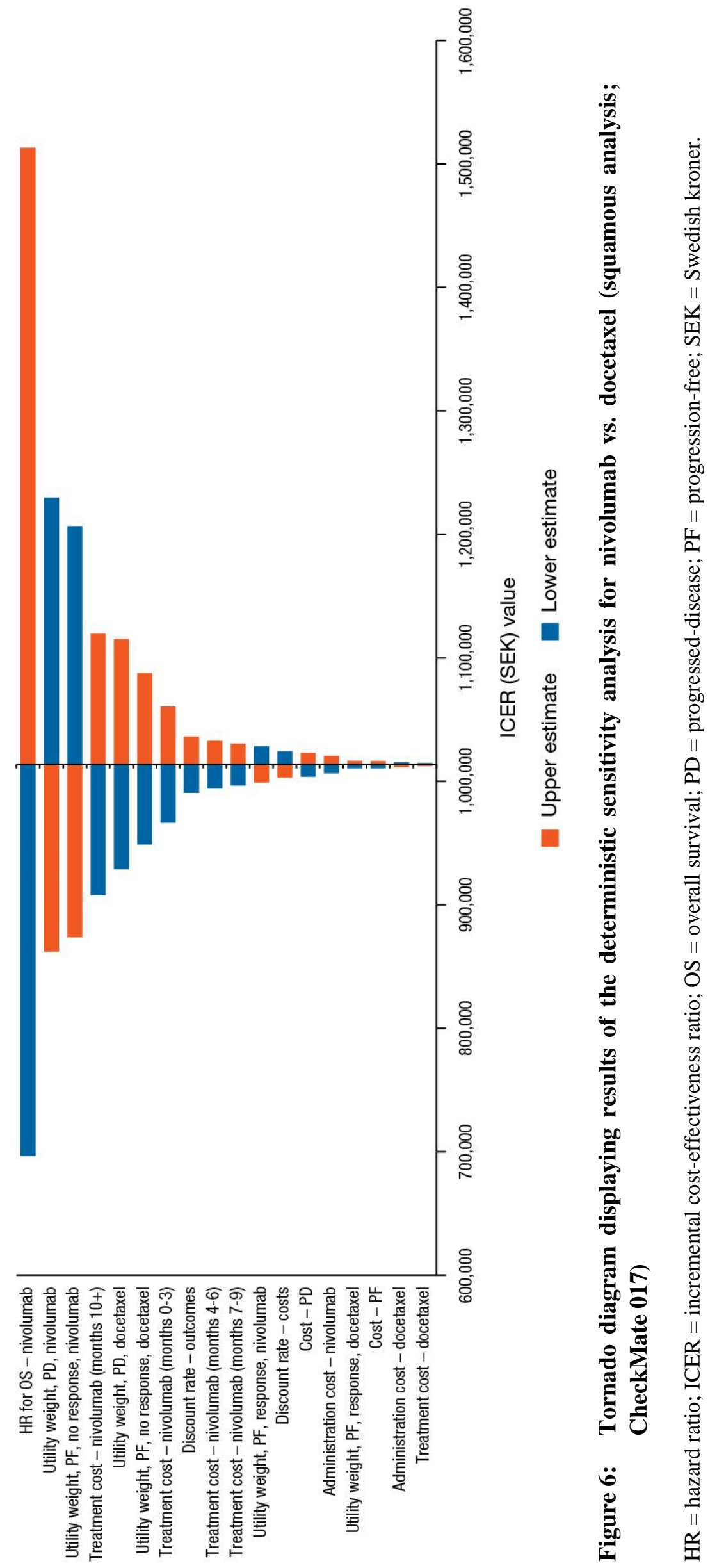


PSA for nivolumab versus docetaxel resulted in an incremental cost per QALY of $1,266,319$ SEK $(€ 119,248)$. Of the 1,000 iterations run for the PSA, 95\% fell within a range of 829,523 SEK $(€ 78,115)$ to $2,249,617$ SEK $(€ 211,844)$ incremental cost per QALY. When applying a treatment-stopping rule at 96 weeks, the PSA for nivolumab versus docetaxel resulted in an incremental cost per QALY of 602,644 SEK ( $€ 56,750)$. Of the 1,000 iterations run for the PSA, 95\% fell within a range of 407,316 SEK (€38,357) to 1,042,287 SEK $(€ 98,151)$ incremental cost per QALY. The CEACs illustrating these findings are shown in Figure S3 and Figure S4.

Table 4: Base-case cost-effectiveness results (non-squamous analysis; CheckMate 057)

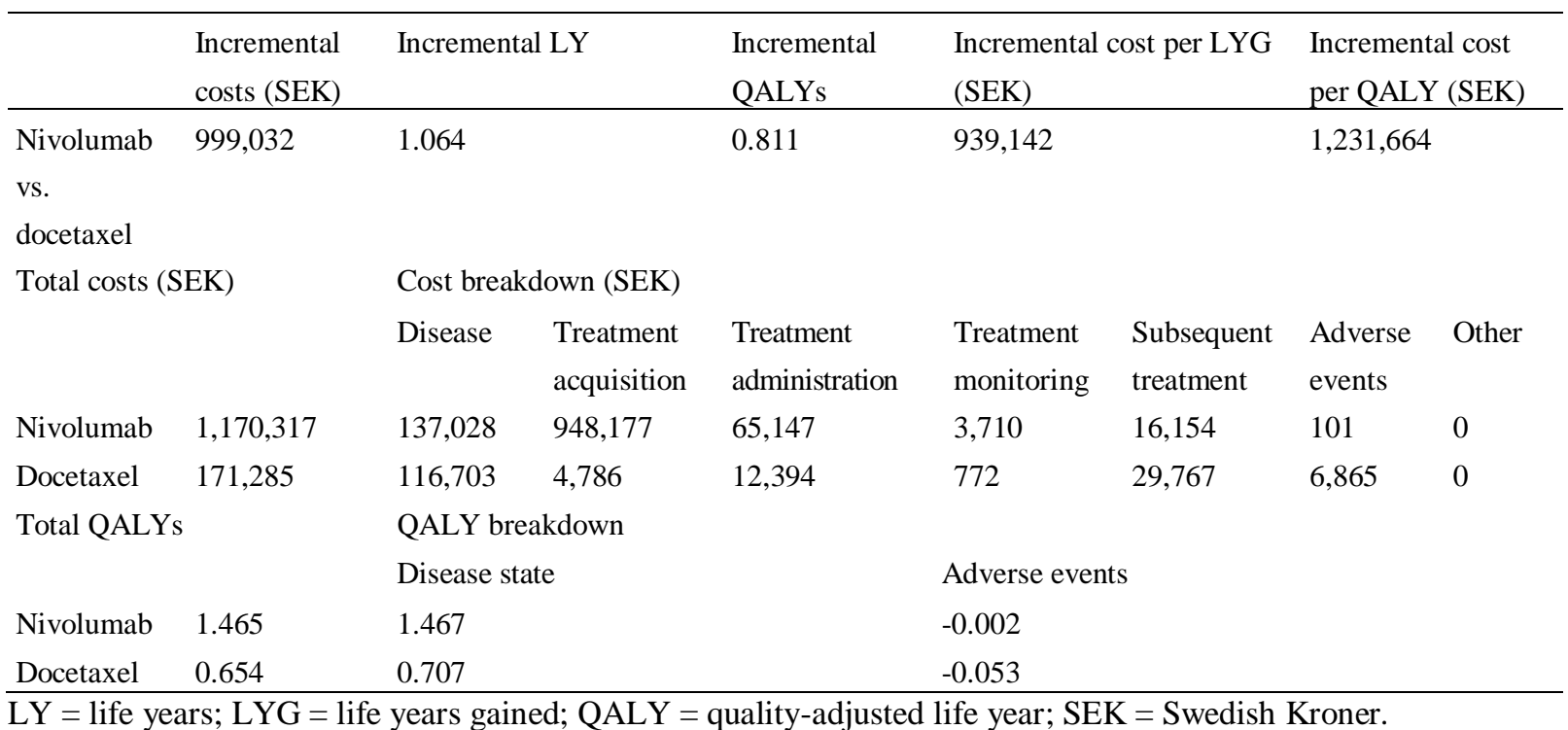

$\mathrm{LY}=$ life years; $\mathrm{LYG}=$ life years gained; $\mathrm{QALY}=$ quality-adjusted life year; SEK = Swedish Kroner.

\section{Discussion}

This analysis showed that the incremental cost-effectiveness ratios (ICERs) for nivolumab versus docetaxel in squamous and non-squamous NSCLC were estimated to be 1,013,697 SEK $(€ 95,459)$ and 1,231,664 SEK $(€ 115,985)$, respectively, in the Swedish setting. Increased life expectancy and quality of life associated with nivolumab resulted in a QALY gain versus docetaxel of 0.72 and 0.81 in patients with squamous and non-squamous NSCLC, respectively. However, these incremental benefits were achieved at higher incremental costs versus docetaxel $(734,573$ SEK $[€ 69,174]$ and 999,032 SEK [€94,078]) in squamous and non-squamous NSCLC, respectively. Most of these costs were attributed to nivolumab drug acquisition; in addition to a higher cost per dose, nivolumab is associated with longer treatment duration than docetaxel as patients remain progression-free for longer (Borghaei et al. 2015, Brahmer et al. 2015). The base-case findings indicate that the price of nivolumab is a driver of cost-effectiveness. 


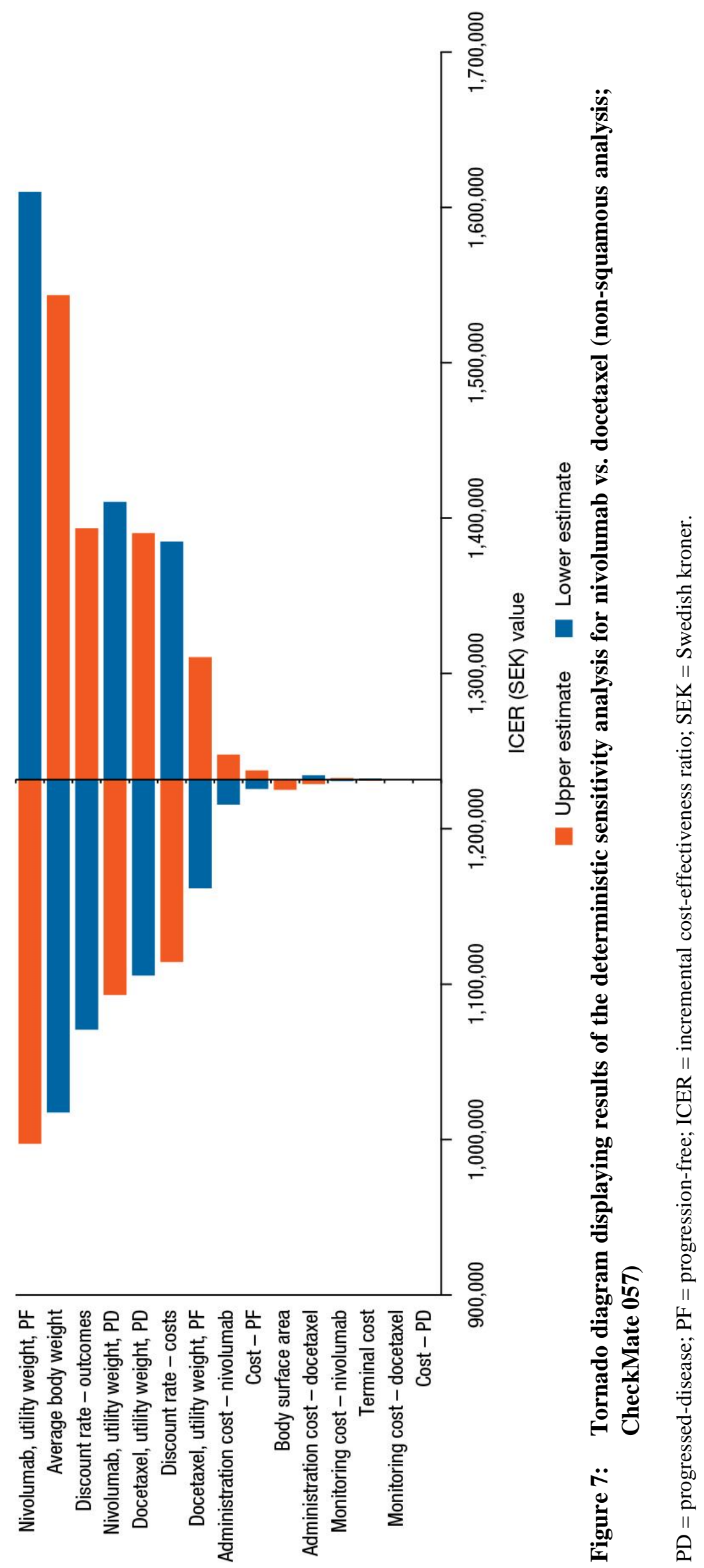


These findings are generally consistent with those observed in the TLV appraisal (Tandvårds- och läkemedelsförmånsverket 2017). For squamous NSCLC, the TLV concluded that the incremental cost per QALY for nivolumab versus docetaxel was likely in the range of $900,000 \mathrm{SEK}(€ 84,752)$ to $1,370,000 \mathrm{SEK}(€ 129,012)$. In non-squamous NSCLC, the TLV concluded that the incremental cost per QALY for nivolumab versus docetaxel was likely in the range of $630,000 \mathrm{SEK}(€ 59,327)$ to $1,070,000 \mathrm{SEK}(€ 100,761)$. Based on these findings, the New Therapies Council recommended nivolumab as a costeffective treatment option for squamous and non-squamous NSCLC in Sweden (The New Therapies Council 2019). It must be noted that our ICER value in non-squamous NSCLC (1,231,664 SEK) was slightly higher that that reported by the TLV (1,070,000 SEK). However, it was lower than a 2016 Swedish model, based on CheckMate 057 data, that resulted in a base-case ICER of 177,478 CHF (1,688,742 SEK); these authors concluded that reduced nivolumab price, dose, or treatment duration could decrease the ICER (MatterWalstra et al. 2016). The difference in the ICER values obtained between these models could be due to a range of factors, including model used, data sources, extrapolations, and price lists. It is beyond the scope of this article to address these methodology differences in detail.

In our model, we also showed that applying a 96-week treatment-stopping rule reduced the ICER to 719,268 SEK (€67,733) per QALY in squamous and 593,702 SEK $(€ 55,908)$ per QALY in non-squamous NSCLC. The TLV considered a scenario with a maximum treatment duration of 96 weeks. With a generalized gamma model to extrapolate time-to-treatment discontinuation and the use of a 96-week treatment-stopping rule, the ICER decreased to 600,882 SEK (€56,584). However, the TLV highlighted that further clinical evidence was required to support the efficacy of nivolumab beyond treatment cessation (Tandvårds- och läkemedelsförmånsverket 2017). Furthermore, the model also showed that when applying Swedish utility weights the ICER reduced to 855,505 SEK $(€ 80,562)$ per QALY in squamous and $1,165,401$ SEK $(€ 109,745)$ per QALY in nonsquamous NSCLC. The decrease in the cost per QALY is driven by the fact that Swedish health utility weights were higher than those for the UK (Table 1 and Table 2), which has been validated an independent trial (Aronsson et al. 2015).

Assessing uncertainty in the PSA yielded similar results to the base-case in our model. The PSA in each model was run for 1,000 iterations and yielded an ICER of $1,045,419$ SEK $(€ 98,446)$ and $1,266,319$ SEK $(€ 119,248)$ in squamous and non-squamous NSCLC, respectively. The DSA showed that the models were most sensitive to utility values, body weight, long-term treatment costs and discount rates (outcomes).

\subsection{Strengths and limitations}

The models were based on the versions submitted to the TLV (Tandvårds- och läkemedelsförmånsverket 2017). In its appraisal, the TLV found the model structure to be appropriate, and the inputs and assumptions to be in line with previous submissions. The model was also derived from robust data from randomized trials (CheckMate 017 and 057). Health state utility weights were calculated from data collected directly from patients in CheckMate 017 and 057 and did not require extrapolation or use of external evidence. Extrapolations based on the clinical data (OS and PFS) were extensively validated against external trials such as CheckMate 003 and CheckMate 063 and real-world datasets, including SEER program data (Bristol-Myers Squibb 2015a, Gettinger et al. 2015, Rizvi et al. 2015). Though the original models were submitted to the TLV based on 12- and 18month data for squamous and non-squamous respectively, it is evident from longer followup in CheckMate 003 (up to 5 years) and in CheckMate 017 and 057 (up to 3 years) that the base-case extrapolations remain appropriate and valid. The largest uncertainty in the model 
is longer-term nivolumab OS. The 3-year nivolumab OS rates predicted by the original models were $17.4 \%$ and $19.4 \%$ in squamous and non-squamous NSCLC respectively; in comparison, the longer follow-up from CheckMate 017 and 057 estimated 3-year nivolumab OS rates of $15.6 \%$ and $17.7 \%$, respectively. Therefore, longer follow-up from the trials has validated the robustness of the original extrapolations.

The cost-effectiveness analyses have many limitations. First, only grade $3 / 4$ adverse events were included. In addition, the disutility of adverse events was not available from the trial data, but was sourced from the published literature. However, adverse events contribute to less than $1 \%$ of the incremental costs and QALYs of nivolumab versus docetaxel; thus, the impact of adverse events on the economic model results is small. Furthermore, since nivolumab has a more favourable toxicity profile than docetaxel, it is likely that the exclusion of some adverse events would make the model conservative.

Second, the usual modelling approach with PFS as a proxy for treatment duration presented challenges in modelling nivolumab in these two trials, as treatment was allowed beyond initial radiographic progression. To validate this assumption, PFS versus time-totreatment discontinuation was tested in both models. For the squamous analysis, nivolumab PFS and time-to-treatment discontinuation were superimposed; therefore, this assumption had a marginal impact on the results. For the non-squamous analysis, nivolumab time-totreatment discontinuation was greater than PFS, so time-to-treatment discontinuation was used as a proxy for PFS in the base-case. Therefore, this assumption was not required in the base-case of the non-squamous model.

Third, ICERs as a function of nivolumab price were considered in the sensitivity analyses and not the base-case model. However, these sensitivity analyses showed that an overwhelming driver of cost-effectiveness was long-term treatment cost (squamous) and discount rates (non-squamous).

\subsection{Policy implications}

The New Therapies Council has recommended use of nivolumab, following the TLV appraisal that nivolumab is a cost-effective treatment option for previously treated patients with squamous or non-squamous NSCLC in Sweden. Our model further supports these findings.

\section{Conclusions}

This cost-effectiveness analysis demonstrated that increased life expectancy and improvements in quality of life associated with nivolumab resulted in a QALY gain versus docetaxel of 0.72 and 0.81 in squamous and non-squamous NSCLC patients, respectively. These gains were at a higher incremental cost of 734,573 SEK $(€ 69,174)$ and 999,032 SEK (€94,078), which was driven mainly by nivolumab acquisition costs. The resulting ICERs for nivolumab versus docetaxel were estimated at 1,013,697 SEK (€95,459) and 1,231,664 SEK $(€ 115,985)$ in squamous and non-squamous NSCLC, respectively. Based on these findings, nivolumab was deemed a cost-effective treatment option for squamous and nonsquamous NSCLC in Sweden in accordance with previous appraisals by the Dental and Pharmaceutical Benefits Agency (TLV) and New Therapies council in Sweden.

\section{Conflicts of interest}

CS, MV, EM, and MH are employees of Parexel, which was contracted by Bristol-Myers Squibb to develop the economic model. JRP, NH, ML, and CH are employees of Bristol-Myers Squibb, which markets nivolumab. 


\section{Roles and responsibilities}

CS: Lead modeller for the development of the global economic model for CheckMate 017 and 057. MV: Project lead for the development of the global economic model for CheckMate 017 and 057. EM: Review and sign-off of the Swedish adaptation of the global model for CheckMate 017 and 057. MH: Project lead for the Swedish adaption of the global model for CheckMate 017 and 057. JRP: Review and sign-off of the global economic model for CheckMate 017 and 057. NH: Review and sign-off of the global economic model for CheckMate 017 and 057. ML: Review and sign-off of the global economic model for CheckMate 017 and 057. CH: Review and sign-off of the Swedish adaptation of the global model for CheckMate 017 and 057.

The work was sponsored by Bristol-Myers Squibb, which was involved in the design, data collection, data analysis, manuscript preparation, and manuscript review.

\section{Acknowledgements}

Medical writing and editorial assistance were funded by Bristol-Myers Squibb and provided by Parexel International.

This study was not submitted to ethics committee consideration.

Exchange rate used (July 2019): 1 Euro $=10.6192$ SEK, 1 CHF $=9.51522$ SEK.

\section{References}

Antonia, S.J., Brahmer, J.R., Gettinger, S.N., Quan Man Chow, L., Juergens, R.A. and Shepherd, F.A. (2014). Nivolumab (anti-PD-1; BMS-936558, ONO-4538) in Combination With Platinum-Based Doublet Chemotherapy (PT-DC) in Advanced Non-Small Cell Lung Cancer (NSCLC), Journal of Clinical Oncology, 32(15_suppl), 8023-8023.

Apoteket. Apoteket 2015. https://www.apoteket.se/. Last accessed 10 July 2019.

Aronsson, M., Husberg, M., Kalkan, A., Eckard, N. and Alwin, J. (2015). Differences Between Hypothetical and Experience-Based Value Sets for EQ-5D Used in Sweden: Implications for Decision Makers, Scandinavian Journal of Public Health, 43(8), 848-854.

Borghaei, H., Paz-Ares, L., Horn, L., Spigel, D.R., Steins, M., Ready, N.E., Chow, L.Q., Vokes, E.E., Felip, E., Holgado, E., Barlesi, F., Kohlhaufl, M., Arrieta, O., Burgio, M.A., Fayette, J., Lena, H., Poddubskaya, E., Gerber, D.E., Gettinger, S.N., Rudin, C.M., Rizvi, N., Crino, L., Blumenschein, G.R., Jr., Antonia, S.J., Dorange, C., Harbison, C.T., Graf Finckenstein, F. and Brahmer, J.R. (2015). Nivolumab Versus Docetaxel in Advanced Nonsquamous Non-SmallCell Lung Cancer, New England Journal of Medicine, 373(17), 1627-1639.

Brahmer, J., Horn, L., Jackman, D., Spigel, D., Antonia, S., Hellmann, M., Powderly, J., Heist, R., Sequist, L., Smith, D.C., Leming, P., Geese, W.J., Yoon, D., Li, A. and Gettinger, S. (2017). Five-Year Follow-Up From the CA209-003 Study of Nivolumab in Previously Treated Advanced Non-Small Cell Lung Cancer (NSCLC): Clinical Characteristics of Long-Term Survivors, Cancer Research, 77 (Suppl 13), CT077.

Brahmer, J., Reckamp, K.L., Baas, P., Crino, L., Eberhardt, W.E., Poddubskaya, E., Antonia, S., Pluzanski, A., Vokes, E.E., Holgado, E., Waterhouse, D., Ready, N., Gainor, J., Aren Frontera, O., Havel, L., Steins, M., Garassino, M.C., Aerts, J.G., Domine, M., Paz-Ares, L., Reck, M., Baudelet, C., Harbison, C.T., Lestini, B. and Spigel, D.R. (2015). Nivolumab Versus Docetaxel in Advanced Squamous-Cell Non-Small-Cell Lung Cancer, New England Journal of Medicine, 373(2), 123-135.

Bristol-Myers Squibb. OR NIVO 010. Data on file. 2015a.

Bristol-Myers Squibb. OR NIVO 028. Data on file. 2015b. 
Bristol-Myers Squibb. OR NIVO 080. Data on file. 2017.

Burstrom, K., Sun, S., Gerdtham, U.G., Henriksson, M., Johannesson, M., Levin, L.A. and Zethraeus, N. (2014). Swedish Experience-Based Value Sets for EQ-5D Health States, Quality of Life Research, 23(2), 431-442.

Dolan, P. (1997). Modeling valuations for EuroQol health states, Medical Care, 35(11), 1095-1108.

Eisenhauer, E.A., Therasse, P., Bogaerts, J., Schwartz, L.H., Sargent, D., Ford, R., Dancey, J., Arbuck, S., Gwyther, S., Mooney, M., Rubinstein, L., Shankar, L., Dodd, L., Kaplan, R., Lacombe, D. and Verweij, J. (2009). New Response Evaluation Criteria In Solid Tumours: Revised RECIST guideline (version 1.1), European Journal of Cancer, 45(2), 228-247.

European Medicines Agency. OPDIVO. Last updated 22 January 2019. http://www.ema.europa.eu/ema/index.jsp?curl=pages/medicines/human/medicines/003985/hu man_med_001876.jsp\&mid=WC0b01ac058001d124. Last accessed 10 July 2019.

Font, E.F., Gettinger, S.N., Burgio, M.A., Antonia, S.J., Holgado, E., Spigel, D.R., Arrieta, O., Domine Gomez, M., Aren Frontera, O., Brahmer, J., Chow, L.Q., Crinò, L., Butts, C., Coudert, B., Horn, L., Steins, M., Geese, W.J., Li, A., Healey, D. and Vokes, E.E. (2017). Three-Year Follow up From CheckMate 017/057: Nivolumab Versus Docetaxel in Patients With Previously Treated Advanced Non-Small Cell Lung Cancer (NSCLC), Annals of Oncology, 28(Suppl 5), 1301PD.

Gettinger, S.N., Horn, L., Gandhi, L., Spigel, D.R., Antonia, S.J., Rizvi, N.A., Powderly, J.D., Heist, R.S., Carvajal, R.D., Jackman, D.M., Sequist, L.V., Smith, D.C., Leming, P., Carbone, D.P., Pinder-Schenck, M.C., Topalian, S.L., Hodi, F.S., Sosman, J.A., Sznol, M., McDermott, D.F., Pardoll, D.M., Sankar, V., Ahlers, C.M., Salvati, M., Wigginton, J.M., Hellmann, M.D., Kollia, G.D., Gupta, A.K. and Brahmer, J.R. (2015). Overall Survival and Long-Term Safety of Nivolumab (Anti-Programmed Death 1 Antibody, BMS-936558, ONO-4538) in Patients With Previously Treated Advanced Non-Small-Cell Lung Cancer, Journal of Clinical Oncology, 33(18), 2004-2012.

KOL: Swedish NSCLC clinical expert. 2015.

KREFT Registeret. Nasjonalt kvalitetsregister for lungekreft: Årsrapport 2015. https://www.kreftregisteret.no/globalassets/publikasjoner-og-rapporter/arsrapporter/publisert2016/arsrapport-2015-lungekreft.pdf. Last accessed 10 July 2019.

Latimer, N. NICE DSU Technical Support Document 14: Survival analysis for economic evaluations alongside clinical trials - extrapoloation with patient-level data. June 2011 (last updated March 2013). http://nicedsu.org.uk/wp-content/uploads/2016/03/NICE-DSU-TSDSurvival-analysis.updated-March-2013.v2.pdf. Last accessed 10 July 2019.

Matter-Walstra, K., Schwenkglenks, M., Aebi, S., Dedes, K., Diebold, J., Pietrini, M., Klingbiel, D., von Moos, R., Gautschi, O. and Swiss Group for Clinical Cancer Research (2016). A CostEffectiveness Analysis of Nivolumab Versus Docetaxel for Advanced Nonsquamous NSCLC including PD-L1 testing, Journal of Thoracic Oncology, 11(11), 1846-1855.

National Cancer Institute. Surveillance, Epidemiology, and End Results Program. 2019. https://seer.cancer.gov. Last accessed 10 July 2019.

NORDCAN Association of the Nordic Cancer Registries. Cancer Stat Fact Sheets. Sweden - Lung. NORDCAN Database (version 7.3). 25 March 2019. http://wwwdep.iarc.fr/NORDCAN/english/StatsFact.asp?cancer=180\&country=752. Last accessed 10 July 2019.

NordDRG. Sekundär klassificering av diagnosrelaterade grupper (DRG). 2013. https://www.socialstyrelsen.se/utveckla-verksamhet/gemensaminformationsstruktur/klassificering-och-koder/drg/. Last accessed 10 July 2019.

NordDRG. Sekundär klassificering av diagnosrelaterade grupper (DRG). 2014. https://www.socialstyrelsen.se/utveckla-verksamhet/gemensaminformationsstruktur/klassificering-och-koder/drg/. Last accessed 10 July 2019. 
Regionala Cancercentrum I Samverkan. Lungcancer: Årsrapport från Nationella lungcancerregisret (NLCR). 2014. https://www.cancercentrum.se/globalassets/cancerdiagnoser/lunga-ochlungsack/kvalitetsregister/rapport/nlcr_2014_150930.pdf. Last accessed 10 July 2019.

Rizvi, N.A., Mazieres, J., Planchard, D., Stinchcombe, T.E., Dy, G.K., Antonia, S.J., Horn, L., Lena, H., Minenza, E., Mennecier, B., Otterson, G.A., Campos, L.T., Gandara, D.R., Levy, B.P., Nair, S.G., Zalcman, G., Wolf, J., Souquet, P.J., Baldini, E., Cappuzzo, F., Chouaid, C., Dowlati, A., Sanborn, R., Lopez-Chavez, A., Grohe, C., Huber, R.M., Harbison, C.T., Baudelet, C., Lestini, B.J. and Ramalingam, S.S. (2015). Activity and Safety of Nivolumab, an Anti-PD-1 Immune Checkpoint Inhibitor, for Patients With Advanced, Refractory Squamous Non-Small-Cell Lung Cancer (CheckMate 063): a Phase 2, Single-Arm Trial, Lancet Oncology, 16(3), 257-265.

Socialstyrelsen. Nationella vikter för sluten/öppenvårdsgrupper, NordDRG, Prospektiva viktlistor. 2015. https://www.socialstyrelsen.se/utveckla-verksamhet/gemensam-informationsstruktur/ klassificering-och-koder/drg/viktlistor/. Last accessed 10 July 2019.

Södra Regionvårdsnämnden. Regionala priser och ersättningar för södra sjukvårdsregionen. 2014. https://sodrasjukvardsregionen.se/avtal-priser/regionala-priser-och-ersattningar/. Last accessed 10 July 2019.

Södra Regionvårdsnämnden. Regionala priser och ersättningar för södra sjukvårdsregionen. 2015. https://sodrasjukvardsregionen.se/avtal-priser/regionala-priser-och-ersattningar/. Last accessed 10 July 2019.

Södra Regionvårdsnämnden. Regionala priser och ersättningar för södra sjukvårdsregionen. 2018. https://sodrasjukvardsregionen.se/avtal-priser/regionala-priser-och-ersattningar/. Last accessed 10 July 2019.

Tandvårds- och läkemedelsförmånsverket. Hälsoekonomisk bedömning av Opdivo vid lungcancer. 2015. https://www.tlv.se/lakemedel/kliniklakemedelsuppdraget/avslutade-halsoekonomiskabedomningar/arkiv/2015-12-18-halsoekonomisk-bedomning-av-opdivo-vid-lungcancer.html. Last accessed 10 July 2019.

Tandvårds- och läkemedelsförmånsverket. Prissökningar i databsen. 2017. https://www.tlv.se/beslut/sok-i-databasen.html. Last accessed 10 July 2019.

The New Therapies Council. 2019. https://www.janusinfo.se/nationelltordnatinforande/ managedintroductionthisishowitworks/inenglish/thenewtherapiescouncil.5.4771ab7716298ed 82ba9989c.html. Last accessed 10 July 2019.

Union for International Cancer Control. New global cancer data: GLOBOCAN 2018. https://www.uicc.org/new-global-cancer-data-globocan-2018. Last accessed 10 July 2019.

Zappa, C. and Mousa, S.A. (2016). Non-Small Cell Lung Cancer: Current Treatment and Future Advances, Translational Lung Cancer Research, 5(3), 288-300.

(C) 2019 by the author(s). This article is an open access article distributed under the terms and conditions of the Creative Commons Attribution license (http://creativecommons.org/licenses/by/4.0/). 